\title{
Modelling of a novel strong and ductile FRP composite
}

\author{
Wei Sun ${ }^{\mathrm{a}, \mathrm{b}, *}$, Haifeng Liu ${ }^{\mathrm{a}}$, Chunlin Pan ${ }^{\mathrm{a}}$, Tao He ${ }^{\mathrm{a}}$

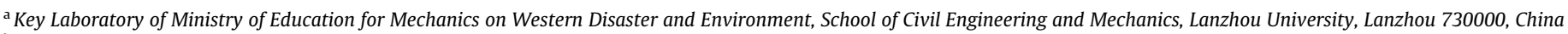 \\ ${ }^{\mathrm{b}}$ Faculty of Engineering and the Environment, University of Southampton, Southampton SO17 1BJ, UK
}

\section{H I G H L I G H T S}

- FE tools were developed to predict the nonlinear responses of FRP composites.

- Comparisons with experimental results were made to demonstrate their reliability.

- The FE tools were expected to aid in further development of the composites

\section{A R T I C L E I N F O}

\section{Article history:}

Received 29 August 2018

Received in revised form 12 January 2019

Accepted 8 May 2019

\section{Keywords:}

FRP helical skins

3D printed cores

High strength

Large deformation

Nonlinear tensile behavior

Finite element

\begin{abstract}
A B S T R A C T
Recently, a novel FRP composite consisting of FRP helical skins and 3D printed cores has been developed. Favorable composite behaviors in terms of high strength, large deformation and notable nonlinear tensile behavior could be achieved by loading helical skins to squeeze inner cores with carefully designed configurations, i.e. shell thickness, core material, brace thickness, brace angle, core number, core height and span. Nevertheless, existing tests resulted in few computational tools for the composite. In this study, a Finite element (FE) model has been calibrated to predict the stress-strain responses for the composite up to skin fracture. Based on the FE predictions for one-core composites, expressions were also proposed for the composites with multiple cores. Comparisons between simulations and corresponding experiments demonstrated reasonable well accordance by using the proposed FE model and expressions, validating their reliability. Those proposed computational tools were expected to aid in further development of more efficient and sophisticated FRP composites upon increasingly updated demands.
\end{abstract}

(c) 2019 Elsevier Ltd. All rights reserved.

\section{Introduction}

Because of their light-weight, high-strength and non-corrosion properties, Fiber Reinforced Polymer (FRP) composites are remarkable materials to strengthen or reinforce concrete structures [1-9]. The successful usage of FRP composites to replace steel reinforcements also suggests an over $\$ 8$ billion annual savings from repairing the corroded components of U.S. bridges [10,11]. However, inadequate deformation resulted from catastrophic brittle failure of FRP rupture limits their vast potentials for structural components. The explorations of fabricating FRP composite with adequate deformability assuring safe, stable and progressive failure mechanisms is therefore of high interest.

FRP composites consisting of 3D printed cores (i.e. inner cores used for shaping outer skins and providing designable core stiffness, strength and deformation under skin squeezing), FRP helical

\footnotetext{
* Corresponding author.

E-mail address: wsun@lzu.edu.cn (W. Sun).
}

skins (squeezing inner cores to unfold shaped skins and resisting the opening at the core edges) have recently been developed to provide stable nonlinear tensile behavior as shown in Fig. 1(a)(b) [12]. The composite could be extended by using multiple cores and bridges (i.e. using helical skins to wrap the inner columns between two cores as shown in Fig. 1(c)). As shown in Fig. 1(c)(d), inner braces have been designed to strengthen inner cores for achieving stiffer composite behaviors. Under tensile loading, helical skins would be further twisted to effectively resist skincore delamination. The proposed composite was therefore expected to suffer from less thermal [13] and UV [14] impacts than existing composites in exclusive usage of epoxy resin to bond their elements [15-18]. Compared with available composites relying on either epoxy bond [15] or stitches $[19,20]$ to connect outer skins with inner cores, those helically twisted skins were also expected to resist much higher opening stresses concentrated at the core edges due to the core stiffness. Then, notable nonlinear composite responses could be stably achieved at high stresses, unfolding remarkably shaped skins to develop large composite deformation. 


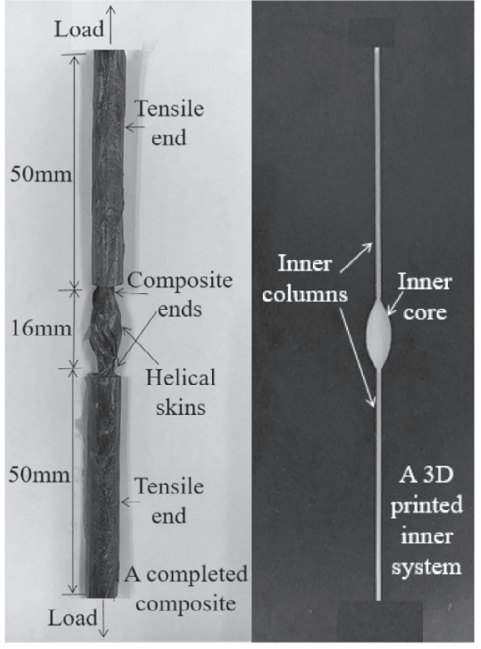

(a) A typical composite with a single core

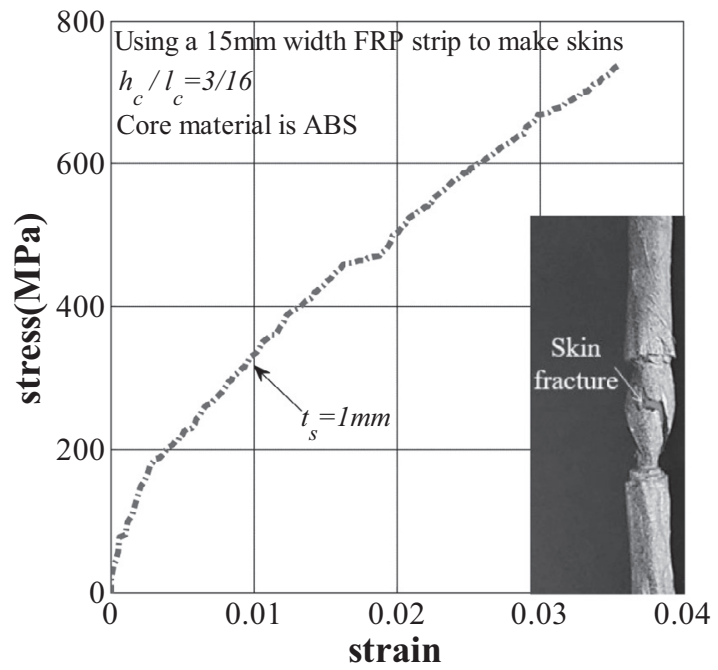

(b) A typical test (A-ii-5)

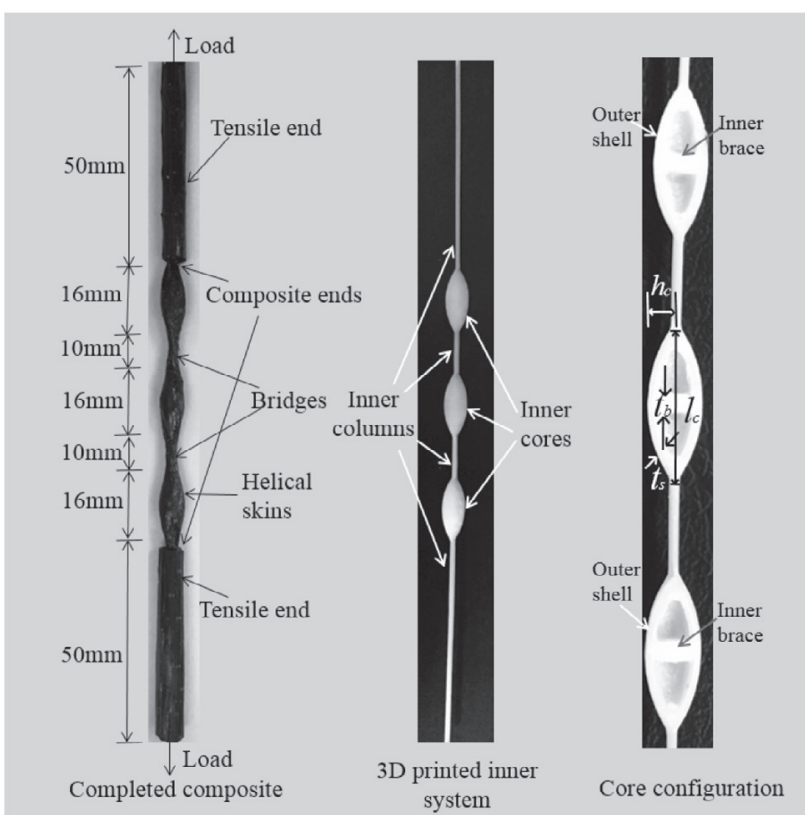

(c) A typical composite with multiple cores

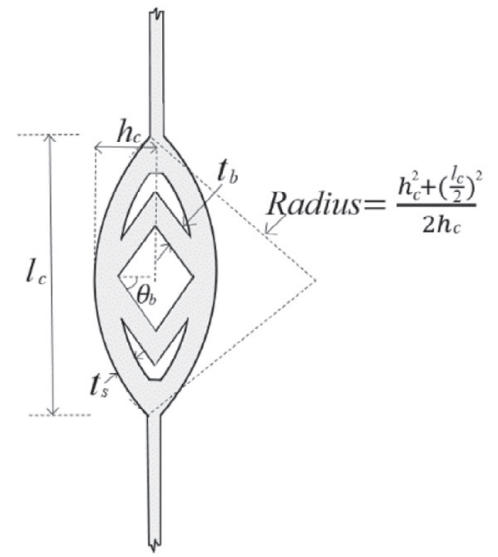

(d) Core configuration

Fig. 1. The proposed composite.

Although experimental results have demonstrated favorable composite responses [12], few computational tools have been calibrated for the composite. This paper aims to calibrate a Finite Element (FE) tool that are best suited for predicting the tensile behavior for the composites having various FRP amounts, core materials and configurations, i.e. core height $h_{c}$, core span $l_{c}$, shell thickness $t_{s}$, brace thickness $t_{b}$, and brace angle $\theta_{b}$. It tends to be computationally efficient and can be easily built by analytical elements with a limited number of inputs that are common to most structural analysis software. Based on the FE predictions for onecore composites, expressions will be proposed for the corresponding composites with multiple cores. The ultimate goal of this study is to provide the needed FE models and expressions for aiding in further development of more efficient and robust FRP composites upon increasingly updated demands.

\section{Modelling background}

Currently, numerical modelling of the composite with stiff skins and inner cores is relatively few in number. In those available studies, stiff skins have been modelled as either an orthotropic [15] or isotropic [20] material with linear-elastic properties. Nevertheless, numerous computational models have successfully applied either orthotropic $[1,2,5]$ or isotropic [21-24] elements to simulate the tensile behavior of FRP material in strengthening concrete structures. Few differences were found between those two methods if those FRP composites were under pure tensile loading [25]. On the other hand, inner cores have been modelled as an isotropic material with corresponding material properties [15,20]. In this study, inner systems consisting of columns and various cores have been printed by Acrylonitrile Butadiene Styrene (ABS) or Polylactic 
Acid (PLA), which were well modelled as elastic-plastic materials [26-29]. However, the damage mechanism of both ABS and PLA materials, depending on pore properties, filament orientation, Poisson's effect and printing resolution, could be varying from case to case. It should be noted that the premature failure of core crush prevented the tensile strength of FRP skins from being fully developed and it therefore was not preferable. Instead, composites developed considerable stresses and strains at skin fracture. In order to achieve computationally efficient predictions, this study intends to provide FE models and expressions for those composites failed in skin fracture. Elastic-plastic models without damage definition are therefore applied to describe the loading behavior of both ABS and PLA materials.

\section{Experimental program}

The proposed FE model was developed using tensile test data. Fig. 1 (a) shows a typical specimens for the tensile test. Both tensile ends of specimens were wrapped and strengthened by $50 \times 50 \mathrm{~mm}$ FRP strips with fibers oriented in the loading direction. Specimens with various configurations and FRP amounts were loaded at $2 \mathrm{~mm} / \mathrm{min}$ until skin fracture (see. Fig. 1(b)). The experimental program was designed to explore the impacts of key parameters, i.e. FRP amount (made by $10 \sim 20 \mathrm{~mm}$-width FRP strips), shell thickness $t_{s}(=1 \sim 2 \mathrm{~mm})$, core material (ABS or PLA), brace thickness $t_{b}(=1 \sim 2 \mathrm{~mm})$, brace angle $\theta_{b}\left(=0^{\circ} \sim 60^{\circ}\right)$, core height $h_{c}(=2 \sim 4 \mathrm{~mm})$, core span $l_{c}(=16 \mathrm{~mm})$ and core numbers $(=1 \sim 3)$, on the tensile behavior of the proposed composite. Core configurations are shown in Fig. 1(c)-(d) and listed in Table 1. Properties of FRP and core materials are listed in Table 2.

A typical stress-strain curve of the composite specimen is presented in Fig. 1(b). Nominal strain $\varepsilon_{\text {comp }}$ is the relative displacement of two points at the composite ends (see. Fig. 1(a)), obtaining from a high-resolution digital image correlation (DIC) system. It should be noted that the composite ends are the last points on the axis of the composite and they are next to the tensile ends. Nominal composite stresses $f_{\text {comp }}$ can be described by the following equation:

$f_{\text {comp }}=P /\left(w_{f} t_{f}\right)$ where

$P=$ the applied load, $\mathrm{N}$,

$w_{f}=$ the measured width of the FRP strip used to make helical skins, $\mathrm{mm}$.

$t_{f}=$ the nominal thickness $(0.51 \mathrm{~mm})$ of the FRP strip used to make helical skins, $\mathrm{mm}$.

Fig. 1(b) shows that the typical stress-strain responses consisting of two phases. At the beginning, the typical test developed almost linear stress-strain responses, which suggested elastic core deformations unfolding proportional amounts of shaped skins to the increased loads. Then, a further loading resulted in plastic core deformation allowing larger extensions to be developed. During that phase, nearly linear but softer stress-strain responses were observed. Ultimately, the test achieved a considerable ultimate stress (737 MPa) and strain (0.036) at skin fracture.

Based on experimental results, it was found that (1) increasing FRP amount resulted in larger composite deformations and increasingly notable nonlinear responses; (2) softening inner core (by reducing shell thickness, increasing the value of $h_{c} / l_{c}$, or using soft core material (like ABS)) developed notable nonlinear tensile responses with favorable ultimate strains; (3) using multiple cores to extend the composite was feasible.

\section{Proposed computational model}

The computational model has been built using the FE package ANSYS [30]. Generally, axial stiffness of wire, inter-wire contact and Poisson's ratio were those key parameters for simulating helical strands under tensile loading. More complex models also considered the impacts of bending and torsion stiffness of wire [31,32]. Since this study aimed to provide with a simple but robust FE model, assumptions have been made to simulate the helical skin bonded to the core surface. It was assumed that the opening angle (i.e. due to skin openings at core edges) instead of the helix angle determined the ultimate load to fracture skin. Skin profiles were therefore simplified as circular-arc shapes with the height $h_{c}$ and span $l_{c}$ defined in Fig. 1(d) and listed in Table 1,

Table 1

Specimen details.

\begin{tabular}{|c|c|c|c|c|c|c|c|c|c|c|c|}
\hline Name & Group & Set & FRP strip width(mm) & $t_{s}(\mathrm{~mm})$ & $t_{b}(\mathrm{~mm})$ & $\begin{array}{l}\text { Brace } \\
\text { number }\end{array}$ & $\theta_{b}\left({ }^{\circ}\right)$ & $h_{c}(\mathrm{~mm})$ & Core number & $l_{c o l}(\mathrm{~mm})$ & Material \\
\hline Simulation 1 & A & $\mathrm{i}$ & 10 & 1 & - & - & - & 3 & 1 & - & ABS \\
\hline Simulation 2 & & ii & 15 & 1 & - & - & - & 3 & 1 & - & ABS \\
\hline Simulation 3 & & iii & 20 & 1 & - & - & - & 3 & 1 & - & ABS \\
\hline Simulation 4 & B & i & 10 & 1 & - & - & - & 2 & 1 & - & ABS \\
\hline Simulation 5 & & ii & 20 & 1 & - & - & - & 4 & 1 & - & ABS \\
\hline Simulation 6 & C & $\mathrm{i}$ & 15 & 2 & - & - & - & 3 & 1 & - & ABS \\
\hline Simulation 7 & $\mathrm{D}$ & $\mathrm{i}$ & 20 & 1 & - & - & - & 4 & 1 & - & PLA \\
\hline Simulation 8 & $\mathrm{E}$ & $\mathrm{i}$ & 15 & 1 & 2 & 1 & 0 & 3 & 1 & - & ABS \\
\hline Simulation 9 & & ii & 15 & 1 & 1 & 2 & 60 & 3 & 1 & - & $A B S$ \\
\hline Prediction 1 & $\mathrm{~F}$ & $\mathrm{i}$ & 15 & 1 & 2 & 1 & 0 & 3 & 3 & 10 & $\mathrm{ABS}$ \\
\hline Prediction 2 & & ii & 15 & 1 & - & - & - & 3 & 3 & 10 & ABS \\
\hline
\end{tabular}

Notes: $l_{c}=16 \mathrm{~mm}$ for all tests, $l_{c o l}=$ the column length connecting two nearby cores, ${ }^{-}$Not applicable.

Table 2

Material properties.

\begin{tabular}{|c|c|c|c|c|c|}
\hline Material & $\begin{array}{l}\text { Thickness } \\
(\mathrm{mm})\end{array}$ & $\begin{array}{l}\text { Density } \\
\left(\mathrm{g} / \mathrm{cm}^{3}\right)\end{array}$ & Young's modulus (GPa) & $\begin{array}{l}\text { Strength } \\
(\mathrm{MPa})\end{array}$ & Elongation at break \\
\hline $\mathrm{ABS}$ & - & 1.0 & 1.95 & 41 & 0.210 \\
\hline PLA & - & 1.2 & 2.50 & 63 & 0.040 \\
\hline FRP & 0.51 & 1.8 & 94.55 & 1043 & 0.011 \\
\hline
\end{tabular}

Notes: - Not applicable. 


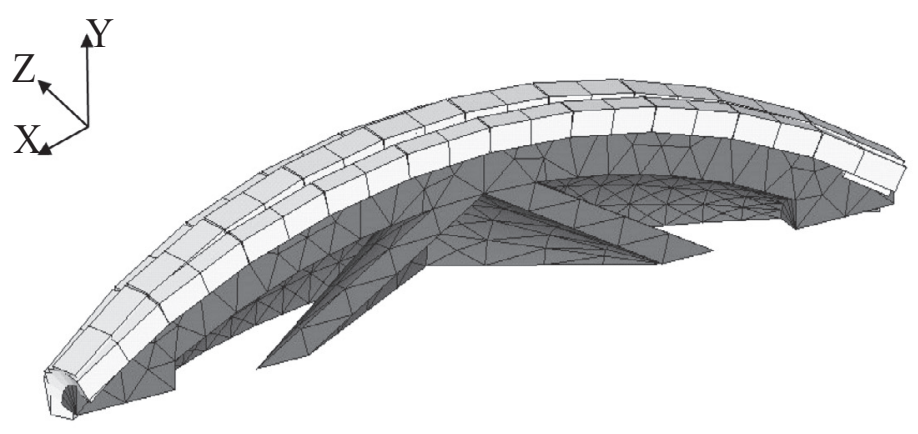

(a) Overview of a typical FE model

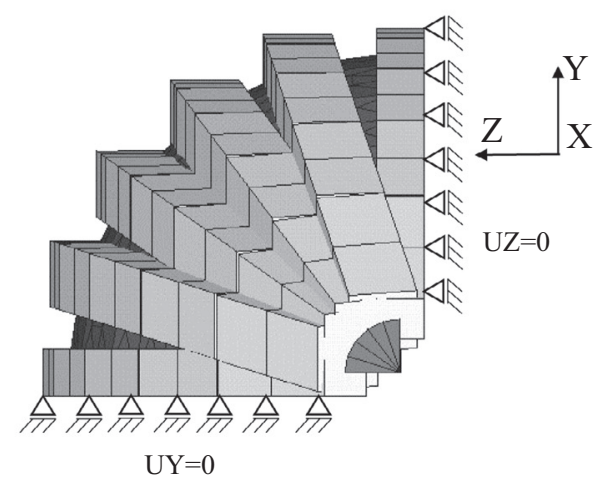

(b) Symmetrical boundary conditions

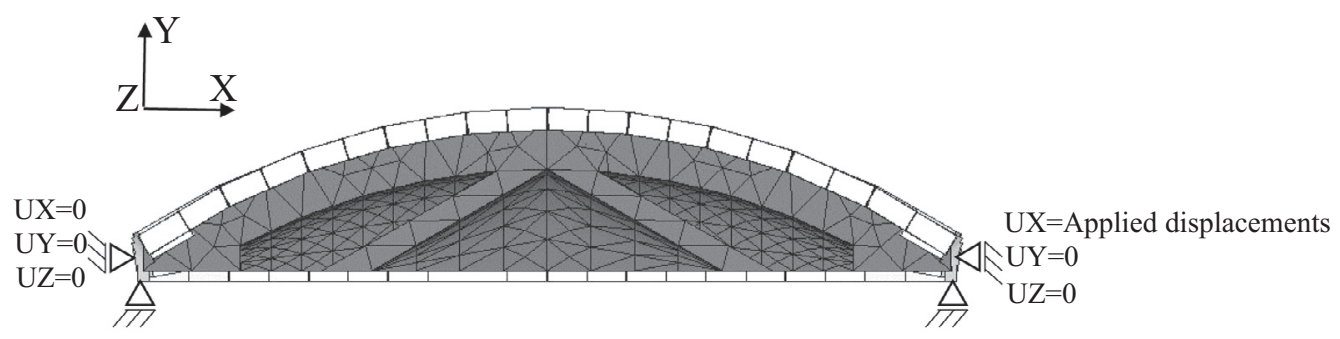

(c) Boundary conditions at both ends

Fig. 2. A typical FE model.

and skin fibers were evenly distributed on the core surface to transfer tensile loads without bending and torsion resistance. All bending and torsion stiffness came from inner cores. Since no debonding failure was observed, a perfect bond has been applied by sharing core nodes with skin elements to describe the skin-core interface.

Based on those assumptions, skin fibers were modeled by twonode truss elements (Link 180). Ten-node tetrahedral structural solid elements (Solid 187) were applied to model inner cores. Due to symmetry, only a quarter of the full composite was built as show in Fig. 2(a). Constraints were applied in the $X Y$ and $X Z$ plane of symmetry to prevent the movements in $\mathrm{Z}$ and $\mathrm{Y}$ direction (see Fig. 2(b)), respectively. Constraints were also applied to prevent any movements at one end of the model. At the other end, movements in $\mathrm{Y}$ and $\mathrm{Z}$ direction were constrained and axial displacements were directly applied on the skin and core nodes as shown in Fig. 2(c). Linear elastic model with an effective modulus of elasticity (see Table 2) was used for simulating skins. Core materials were treated as a linear elastic-perfectly plastic material with manufacturer provided modulus, strength and ultimate strain listed in Table 2. Moreover, the Poisson's ratios of the material used to make skins and cores were 0.2 and 0.4 , respectively (Fig. 3).

\section{Results and discussion}

As listed in Table 1, five groups of simulations (Simulation $1 \sim 9$ corresponding to Group $\mathrm{A} \sim \mathrm{E}$ ) were conducted by using the proposed FE model. Each group consists of at least one simulation, in which FRP amount, the value of $h_{c} / l_{c}$, shell thickness, core material and brace arrangement were varied to match key experimental parameters. In all simulations, the ultimate load was taken when the expected rupture stress (1043 $\mathrm{MPa}$ ) was first reached in any FRP element. Based on simulated curves, expressions were proposed for the composites with multiple cores (i.e. Prediction $1 \sim 2$ corresponding to Group F listed in Table 1 ).

\subsection{Impacts of FRP amount}

Three simulations (Simulation $1 \sim 3$ ) were compared with fifteen tests (No. $1 \sim 15$ listed in Table 3 ) to investigate the impacts 


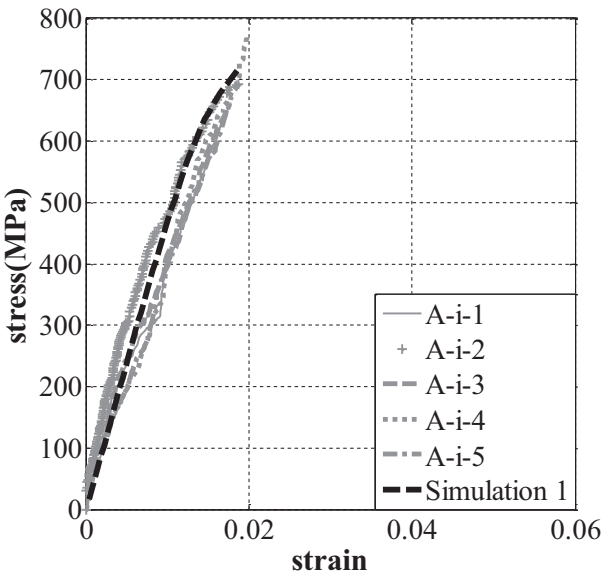

(a)

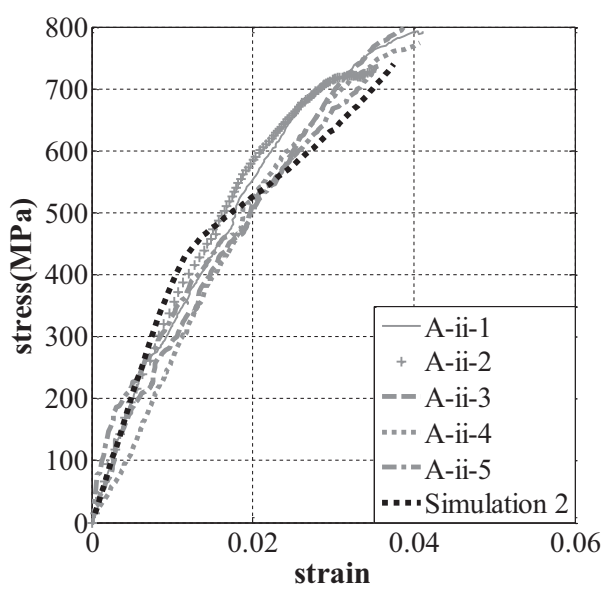

(b)

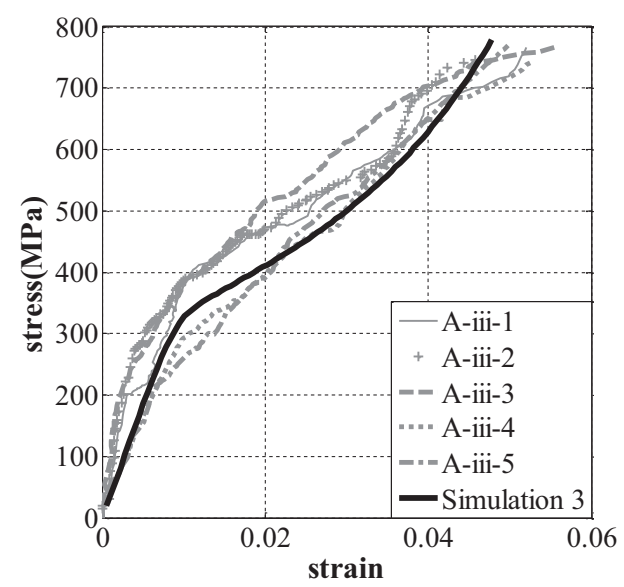

(c)

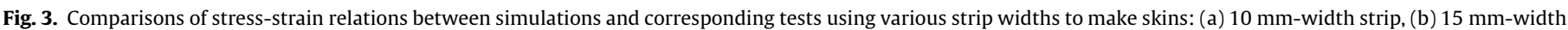
strip and (c) $20 \mathrm{~mm}$-width strip.

of FRP amount. All parameters except FRP amount, i.e. the $h_{c} / l_{c}$ of 3/16, $1 \mathrm{~mm}$-thickness shell and single brace-free core, were kept constant. FRP amount was determined by various FRP strip widths $(10 \sim 20 \mathrm{~mm})$ used to make skins. Table 3 demonstrates numerical predictions are within a good range from $92 \%$ to $108 \%$ of experimental results in terms of ultimate stresses and strains. Inherent variability in nominally identical tests, such as fabrication quality, print resolution and material variability, led to simulations matching some experimental results with higher accuracy than others. Simulation 1 achieved the best predictions in terms of entire stress-strain shapes. Simulation 2 \& 3 matched elastic responses well but tended to produce softer nonlinear predictions compared with corresponding experimental results. Loading speed and filament orientation (i.e. different speeds or orientations used for material tests and composite tests) tended to slightly alter the nonlinear responses of the core material $[27,28]$ which was not perfectly captured by the proposed FE model. Nevertheless, both predicted curves are within a reasonable range from $90 \%$ to $110 \%$ of corresponding experimental measurements through the entire loading process, validating their reliability. Given the core height was $3 \mathrm{~mm}$, the mid-section of the core had $19 \mathrm{~mm}$ perimeters to be covered with $10 \mathrm{~mm}, 15 \mathrm{~mm}$ and $20 \mathrm{~mm}$-width strips. The strip-width/mid-section-perimeter ratio of composites using $10 \mathrm{~mm}, 15 \mathrm{~mm}$ and $20 \mathrm{~mm}$-width strips were $0.53,0.79$ and 1 , respectively. The proposed FE model was therefore expected to provide reliable predictions for those composite using a strip-wid th/mid-section-perimeter ratio from 0.53 to 1 as well.

Fig. 4 illustrates the stress-strain curves of those three directly comparable simulations. By using $10 \mathrm{~mm}$-width strips to make skins, the proposed FE model developed limited nonlinear responses and fractured skins at a relative low stress and strain (717 MPa and 0.019) as listed in Table 3. Increasing the strip width from $10 \mathrm{~mm}$ to $15 \mathrm{~mm}$ resulted in notable nonlinear responses with an increased ultimate stress and strain (740 MPa and 0.038). A continual increasing the strip width from $15 \mathrm{~mm}$ to $20 \mathrm{~mm}$ produced more notable nonlinear responses with a much larger predicted stress and strain at skin fracture (780 MPa and 0.048). In general, increasing FRP amount was expected to develop more notable nonlinear responses, fracture skins at a higher stress and achieve a larger ultimate strain.

\subsection{Impacts of core height and span}

Fig. 5 compares the stress-strain relations of another two simulations (Simulation $4 \sim 5$ ) with ten corresponding tests (No. $16 \sim 25$ listed in Table 3) to evaluate the impacts of core height $h_{c}$ and span $l_{c}$. The core span $(16 \mathrm{~mm})$ was kept constant while increasing core height from $2 \mathrm{~mm}$ to $4 \mathrm{~mm}$ resulted in various $h_{c} / l_{c}$. The strip-width/mid-section-perimeter ratio of 0.79 , which produced stable and improvable stress-strain responses, was used 
Table 3

Comparisons of ultimate stresses and strains between simulations and corresponding tests.

\begin{tabular}{|c|c|c|c|c|c|c|c|}
\hline No. & specimens & Exp. ultimate stresses (MPa) & Pred. ultimate stresses (MPa) & $\%$ of exp. stresses & Exp. Ultimate strains & Pred. ultimate strains & $\%$ of exp. strains \\
\hline 1 & A-i-1 & 663 & 717 & 108 & 0.018 & 0.019 & 106 \\
\hline 2 & $A-i-2$ & 692 & & 104 & 0.019 & & 100 \\
\hline 3 & A-i-3 & 662 & & 108 & 0.018 & & 106 \\
\hline 4 & $A-i-4$ & 776 & & 92 & 0.020 & & 95 \\
\hline 5 & $A-i-5$ & 673 & & 107 & 0.018 & & 106 \\
\hline 6 & A-ii-1 & 794 & 740 & 93 & 0.041 & 0.038 & 93 \\
\hline 7 & A-ii-2 & 737 & & 100 & 0.036 & & 106 \\
\hline 8 & A-ii-3 & 799 & & 93 & 0.039 & & 97 \\
\hline 9 & A-ii-4 & 774 & & 96 & 0.041 & & 93 \\
\hline 10 & A-ii-5 & 737 & & 100 & 0.036 & & 106 \\
\hline 11 & A-iii-1 & 766 & 780 & 102 & 0.053 & 0.048 & 91 \\
\hline 12 & A-iii-2 & 745 & & 105 & 0.046 & & 104 \\
\hline 13 & A-iii-3 & 769 & & 101 & 0.050 & & 96 \\
\hline 14 & A-iii-4 & 741 & & 105 & 0.052 & & 92 \\
\hline 15 & A-iii-5 & 766 & & 102 & 0.052 & & 92 \\
\hline 16 & B-i-1 & 871 & 839 & 96 & 0.011 & 0.012 & 109 \\
\hline 17 & B-i-2 & 910 & & 92 & 0.012 & & 100 \\
\hline 18 & B-i-3 & 782 & & 107 & 0.013 & & 92 \\
\hline 19 & B-i-4 & 776 & & 108 & 0.012 & & 100 \\
\hline 20 & B-i-5 & 769 & & 109 & 0.012 & & 100 \\
\hline 21 & B-ii-1 & 682 & 742 & 109 & 0.084 & 0.092 & 110 \\
\hline 22 & B-ii-2 & 692 & & 107 & 0.091 & & 101 \\
\hline 23 & B-ii-3 & 670 & & 110 & 0.089 & & 103 \\
\hline 24 & B-ii-4 & 684 & & 108 & 0.092 & & 100 \\
\hline 25 & B-ii-5 & 708 & & 105 & 0.092 & & 100 \\
\hline 26 & $\mathrm{C}-\mathrm{i}-1$ & 624 & 675 & 108 & 0.016 & 0.016 & 100 \\
\hline 27 & $\mathrm{C}-\mathrm{i}-2$ & 654 & & 103 & 0.017 & & 94 \\
\hline 28 & $\mathrm{C}-\mathrm{i}-3$ & 662 & & 102 & 0.017 & & 94 \\
\hline 29 & $C-\mathrm{i}-4$ & 624 & & 108 & 0.017 & & 94 \\
\hline 30 & C-i-5 & 653 & & 103 & 0.016 & & 100 \\
\hline 31 & D-i-1 & 506 & 521 & 103 & 0.043 & 0.048 & 110 \\
\hline 32 & D-i-2 & 474 & & 110 & 0.044 & & 109 \\
\hline 33 & D-i-3 & 486 & & 107 & 0.043 & & 110 \\
\hline 34 & D-i-4 & 481 & & 108 & 0.048 & & 100 \\
\hline 35 & D-i-5 & 486 & & 107 & 0.051 & & 94 \\
\hline 36 & E-i-1 & 656 & 709 & 108 & 0.025 & 0.024 & 96 \\
\hline 37 & E-i-2 & 677 & & 105 & 0.024 & & 100 \\
\hline 38 & E-i-3 & 693 & & 102 & 0.026 & & 92 \\
\hline 39 & E-i-4 & 682 & & 104 & 0.025 & & 96 \\
\hline 40 & E-i-5 & 640 & & 110 & 0.022 & & 109 \\
\hline 41 & E-ii-1 & 695 & 710 & 102 & 0.032 & 0.030 & 94 \\
\hline 42 & E-ii-2 & 730 & & 97 & 0.033 & & 91 \\
\hline 43 & E-ii-3 & 677 & & 105 & 0.029 & & 103 \\
\hline 44 & E-ii-4 & 672 & & 106 & 0.028 & & 107 \\
\hline 45 & E-ii-5 & 685 & & 104 & 0.028 & & 107 \\
\hline 46 & F-i-1 & 652 & 710 & 109 & 0.021 & 0.023 & 110 \\
\hline 47 & F-i-2 & 662 & & 107 & 0.022 & & 105 \\
\hline 48 & $\mathrm{~F}-\mathrm{i}-3$ & 674 & & 105 & 0.022 & & 105 \\
\hline 49 & F-i-4 & 706 & & 101 & 0.022 & & 105 \\
\hline 50 & $\mathrm{~F}-\mathrm{i}-5$ & 669 & & 106 & 0.021 & & 110 \\
\hline 51 & F-ii-1 & 710 & 740 & 104 & 0.029 & 0.029 & 100 \\
\hline 52 & F-ii-2 & 706 & & 105 & 0.031 & & 94 \\
\hline 53 & F-ii-3 & 733 & & 101 & 0.026 & & 110 \\
\hline 54 & F-ii-4 & 692 & & 107 & 0.026 & & 110 \\
\hline 55 & F-ii-5 & 763 & & 97 & 0.026 & & 110 \\
\hline
\end{tabular}

Notes: Exp. = experimental value, Pred. = predicted value, all specimens fail in skin fracture.

to calculate the required strip width for FRP skins [12]. The strip widths were therefore $10 \mathrm{~mm}, 15 \mathrm{~mm}$ and $20 \mathrm{~mm}$ for the corresponding composites having $2 \mathrm{~mm}, 3 \mathrm{~mm}$ and $4 \mathrm{~mm}$-height cores, respectively. Except for the core height and strip width, all parameters were kept constant. As shown in Fig. 5, predicted tensile responses agree well with at least one directly comparable experimental result in terms of entire stress-strain shapes, ultimate stresses and strains. Table 3 demonstrates that predicted ultimate stresses and strains are within a good range from $92 \%$ to $109 \%$ of experimental results, further validating their reliability for the composites with $h_{c} / l_{c}$ varying from $2 / 16$ to $4 / 16$.

Fig. 6 illustrates three directly comparable simulations (Simulation 4, 2 and 5) to investigate the impacts of core height. The simulation having a $2 \mathrm{~mm}$-height core fractured skins at a lower ultimate strain than that of the simulation with a $3 \mathrm{~mm}$-height core. A continually increasing core height from $3 \mathrm{~mm}$ to $4 \mathrm{~mm}$ significantly improved the ultimate strain (from 0.038 to 0.092 ) but developed limited increases for the ultimate stress. Moreover, increasing the value of $h_{c} / l_{c}$ from $2 / 16$ to $4 / 16$ tended to produce more notable nonlinear responses starting from lower stresses as shown in Fig. 6.

\subsection{Impacts of shell thickness}

Fig. 7 illustrates the comparison between the simulated curve (Simulation 6) and corresponding tests (No. $26 \sim 30$ listed in Table 3) with a shell thickness of $2 \mathrm{~mm}$. It can be seen that the predicted stress-strain curves agree well with corresponding experi- 


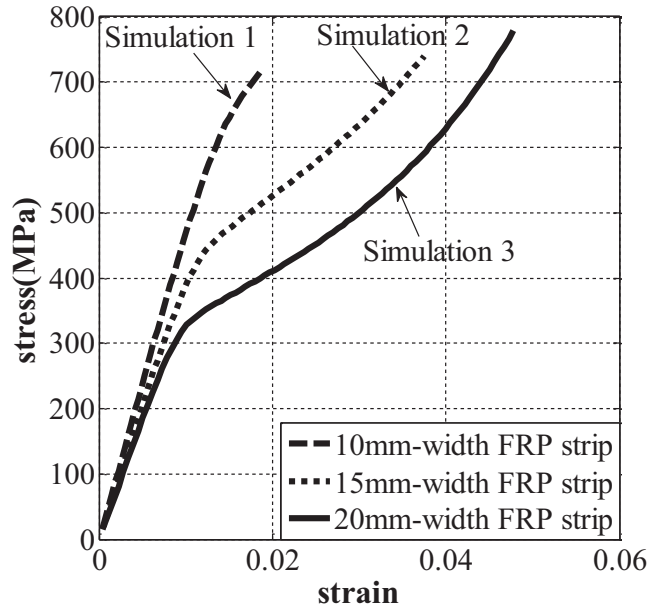

Fig. 4. Predicted stress-strain curves for directly comparable simulations using FRP inputs obtained from various strip widths.

mental results in terms of entire of entire stress-strain shapes. Moreover, the simulation achieved $102 \%$ of the ultimate stress obtained from one directly comparable test (C-i-3) and $100 \%$ of the ultimate strains measured from another two corresponding tests ( $\mathrm{C}-\mathrm{i}-1$ and $\mathrm{C}-\mathrm{i}-5)$ as listed in Table 3 . This suggests that the proposed FE model is capable of well predicting the tensile responses for the composites having a $2 \mathrm{~mm}$-thickness shell. As shown in Fig. 8, a 2 mm-thickness shell was applied in Simulation 6 while keeping other parameters the same as in Simulation 2. It can be seen that increasing shell thickness tends to produce less nonlinear responses, a lower ultimate stress and strain at skin fracture. Within the range investigated, the shell thickness of $1 \mathrm{~mm}$ achieving notable nonlinear responses with a greater stress and strain at skin fracture is more favorable for the composite.

\subsection{Impacts of core material}

Simulated stress-strain relations for five comparable tests (No. $31 \sim 35$ listed in Table 3) are plotted in Fig. 9. The simulation (Simulation 7) is identical to Simulation 5 except for using PLA material to print the core. The PLA material with larger modulus and strength was applied to improve the stiffness of the composite. It can be seen that the simulated elastic-plastic curve agree well with comparable experimental results in terms of entire stress-strain shapes. Moreover, the predicted ultimate stress and strain are

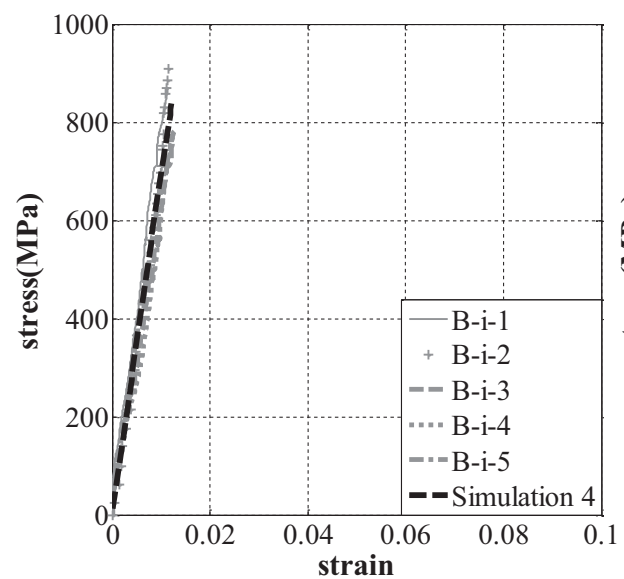

(a)

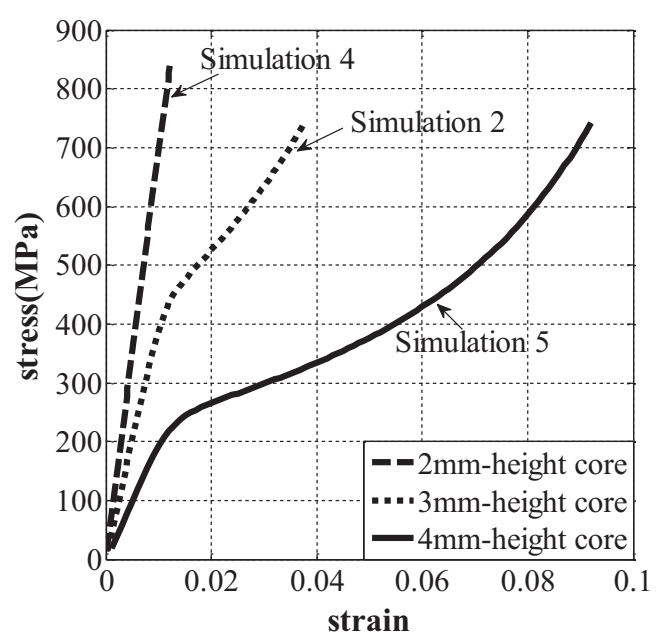

Fig. 6. Predicted stress-strain curves for directly comparable simulations using various height inputs.

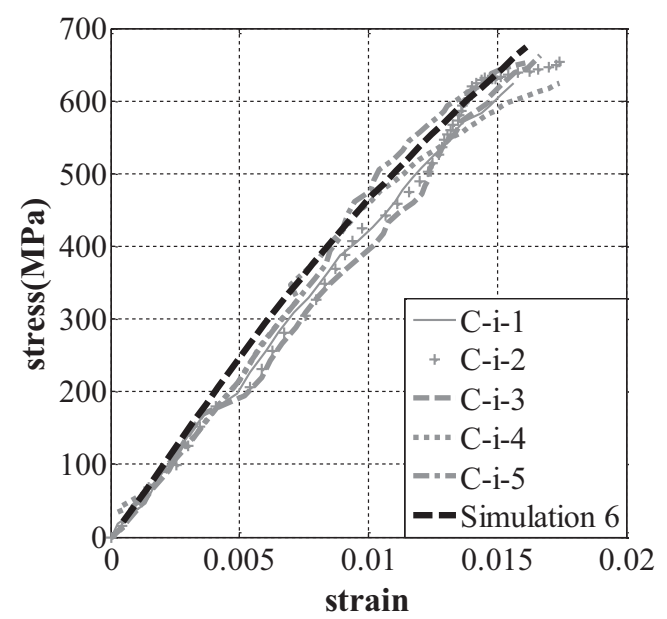

Fig. 7. Comparisons of stress-strain relations between the simulation and corresponding tests having $2 \mathrm{~mm}$-thickness shell.

within a reasonable well range from $94 \%$ to $110 \%$ of comparable experimental results (see Table 3 ), further validating its reliability for the composites having PLA printed cores.

Fig. 10 illustrates the stress-strain relations of two directly comparable simulations (Simulation 5 \& 7) for two core materials (ABS

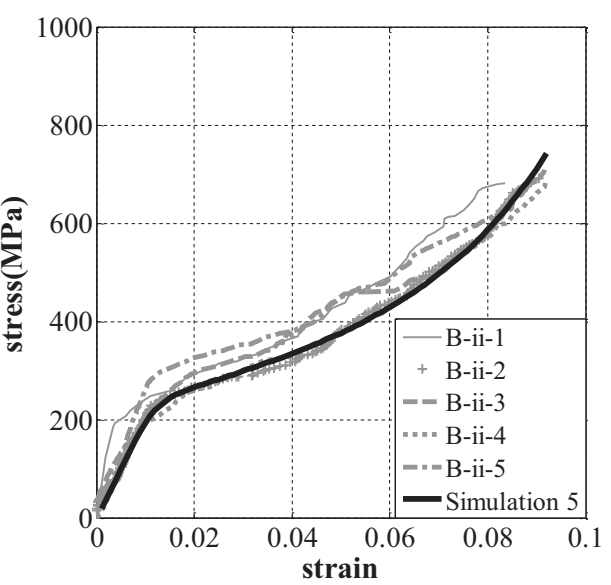

(b)

Fig. 5. Comparisons of stress-strain relations between simulations and corresponding tests using a constant span (16 mm) and various heights: (a) 2 mm and (b) 4 mm. 


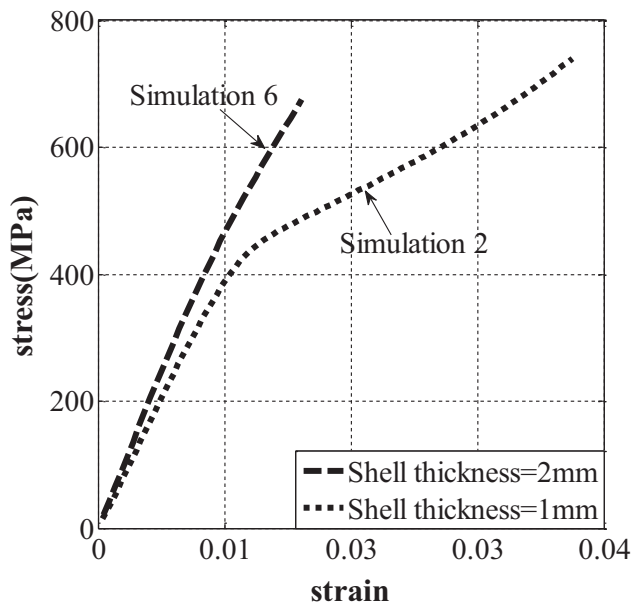

Fig. 8. Predicted stress-strain curves for directly comparable simulations having various shell thicknesses.

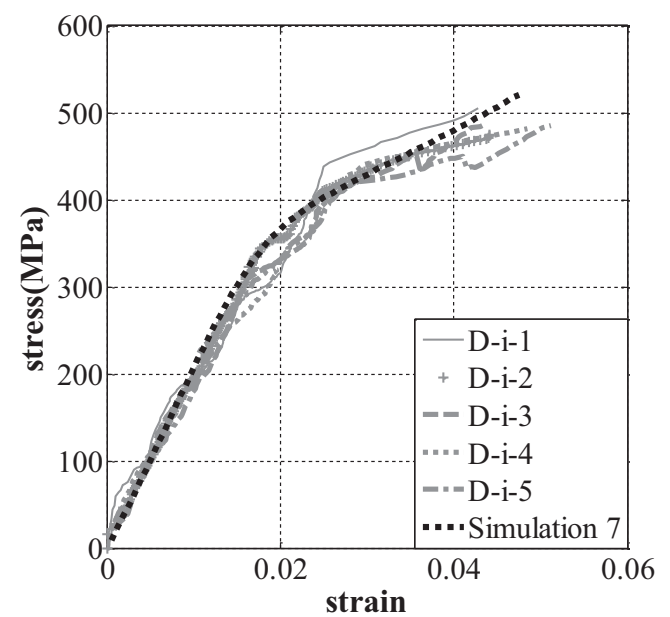

Fig. 9. Comparisons of stress-strain relations between the simulation and corresponding tests using PLA material to print cores.

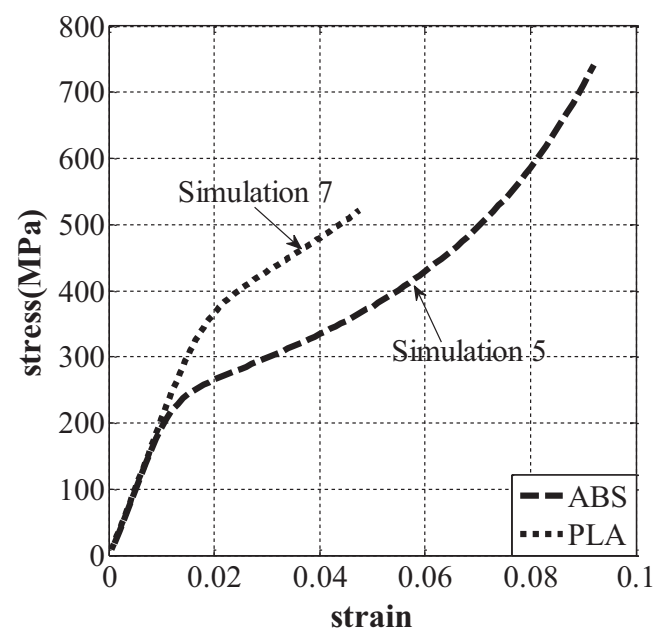

Fig. 10. Predicted stress-strain curves for directly comparable simulations having various core materials.

or PLA). Since both simulations had identical core configuration and FRP amount, core materials with comparable Young's modulus $(\mathrm{ABS}=1.95 \mathrm{GPa}$ and $\mathrm{PLA}=2.50 \mathrm{GPa})$ resulted in few different elas-
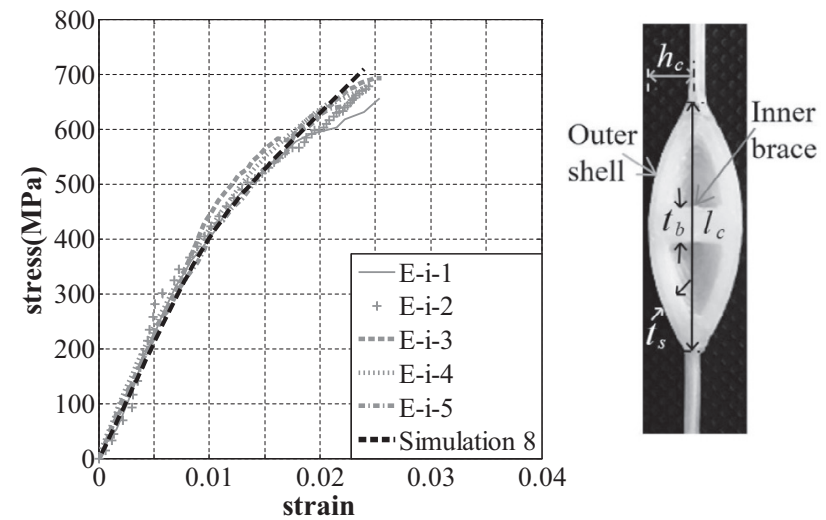

(a)
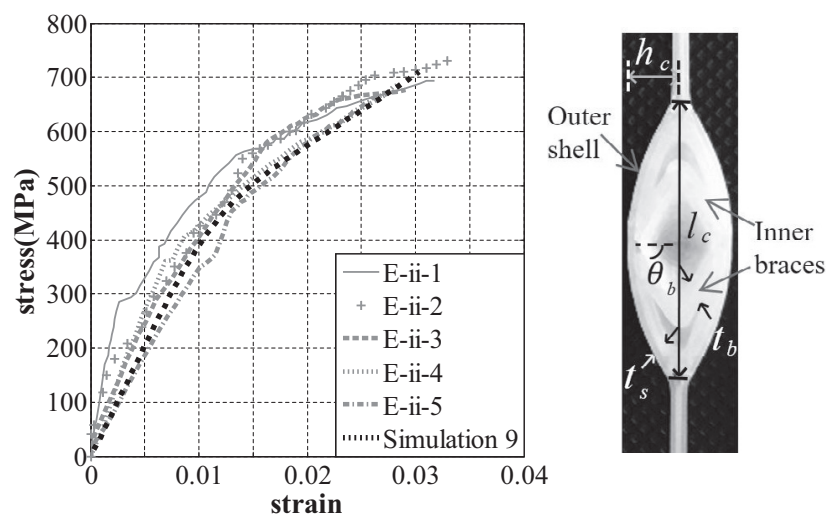

(b)

Fig. 11. Comparisons of stress-strain relations between simulations and corresponding tests having various braces: (a) Brace angle $\theta_{b}=0^{\circ}$ and (b) Brace angle $\theta_{b}=60^{\circ}$.

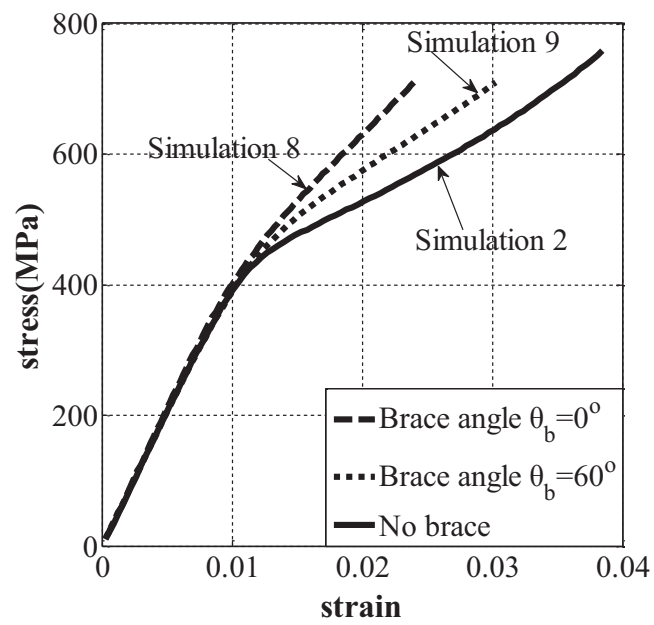

Fig. 12. Predicted stress-strain curves for directly comparable simulations having various braces and no brace.

tic stress-strain curves. However, simulations using PLA inputs started nonlinear responses from a higher stress but developed a much less ultimate stress and strain than that of the simulation using ABS inputs. Thus, a softer material with larger deformability (e.g. ABS) had greater potentials to produce more notable nonlinear responses, larger ultimate stresses and strains. A tougher material with greater modulus tended to result in stiffer composite responses. 


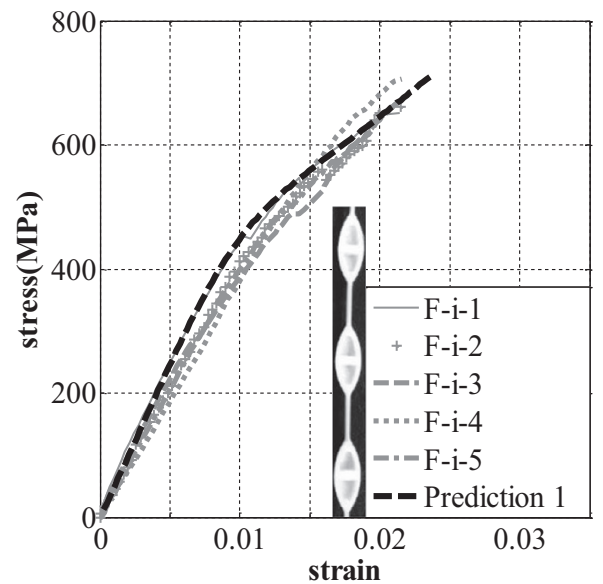

(a)

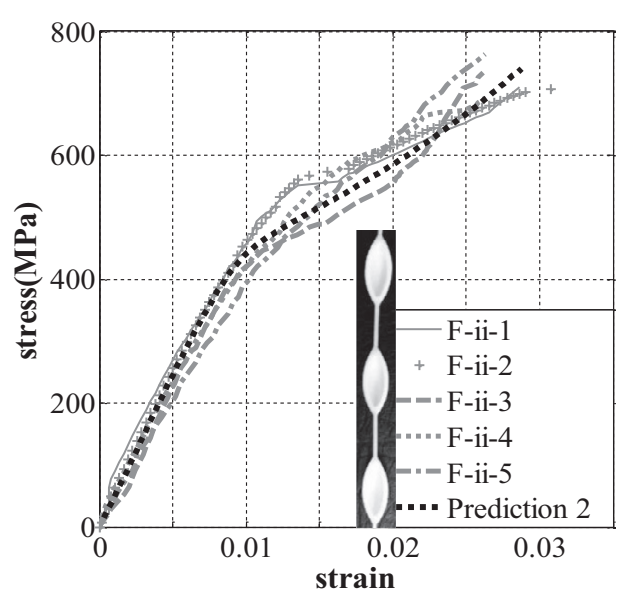

(b)

Fig. 13. Comparisons of stress-strain relations between simulations and corresponding tests having three cores: (a) Brace reinforced cores and (b) Brace free cores.

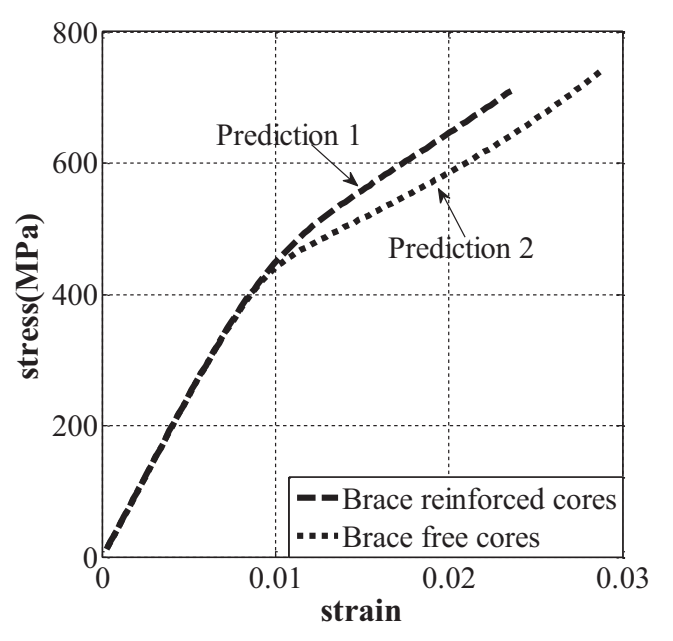

Fig. 14. Predicted stress-strain curves for three-core simulations.

\subsection{Impacts of core brace}

Braces were used in this section to strengthen inner cores and control core deformations as shown in Fig. 11(a)-(b). Two more simulations (Simulation 8 \$9) have been calibrated by ten comparable experimental results (No. $36 \sim 45$ listed in Table 3 ) to evaluate the impacts of core brace. Those braces were either one $2 \mathrm{~mm}$ thickness $\& 0^{\circ}$ brace or two $1 \mathrm{~mm}$-thickness \& $60^{\circ}$ braces as listed in Table 1 . This tended to provide braces with the same entire thickness but various brace angles.

As shown in Fig. 11, simulated curves (Simulation 8 \& 9) agree well with comparable experimental results through the entire loading process. Predicted ultimate stresses and strains also achieve a reasonable well range from $91 \%$ to $110 \%$ of comparable experimental results (see Table 3), indicating the reliability of the proposed FE model for brace reinforced composites. Fig. 12 consists of three simulations with identical configuration and material inputs except for brace applications, i.e. the brace free composite (Simulation 2 ), the $0^{\circ}$ brace reinforced composite (Simulation 8 ) and the $60^{\circ}$ brace reinforced composite (Simulation 9). All simulations produced quite the same elastic stress-strain curves as shown in Fig. 12. The simulation of the composite with $0^{\circ}$ braces produced less notable nonlinear curves and lower ultimate strains than that of the comparable simulations using $60^{\circ}$ braces. Compared with the brace free simulation, brace reinforced simulations resulted in stiffer nonlinear responses but fracture skins at lower stresses and strains. It was because the application of braces limited the core deformation, resulting in a less deformed profile to unfold fewer shaped skins during the entire loading process. Eventually, the less deformed profile fractured skins at a lower stress. Thus, braces had limited contributions to elastic stress-strain responses but were helpful to resist core deformation resulting in stiffer stress-strain responses, lower stresses and strains at skin fracture.

\subsection{Impacts of core number}

Based on the predictions of one-core composites, simple but robust expressions have been proposed to quick determine the stress-strain responses for multiple-core composites with identical core properties. The predicted stress and strain can be expressed as

$f_{c, \text { mult }}=P_{c, \text { mult }} /\left(w_{f} t_{f}\right)$

$\varepsilon_{c, \text { mult }}=\frac{\sigma_{c, \text { mult }}\left(n_{\text {core }} l_{c} / R_{f, s}+n_{\text {col }} l_{\text {col }} / E_{f}\right)}{n_{\text {core }} l_{c}+n_{\text {col }} l_{c o l}}$

$R_{f, s}=f_{\text {comp }} / \varepsilon_{\text {comp }}$

where $f_{c, \text { mult }}$ and $\varepsilon_{c, \text { mult }}$ are the nominal stress and strain under the load $P_{c, \text { mult }}$ applied on the composite with multiple cores; $n_{\text {core }}$ is the number of cores; $n_{c o l}$ is the number of columns; $l_{\text {col }}$ is the column length; $E_{f}$ is the Young's modulus of FRP material (see Table 2). $R_{f, s}$ is the instant ratio of the stress $f_{\text {comp }}$ to the strain $\varepsilon_{\text {comp }}$ obtained from the corresponding simulations for one-core composites.

Fig. 13 shows the predicted and experimental stress-strain responses of the composites having three cores (No. $46 \sim 55$ listed in Table 3). Those brace reinforced (one $2 \mathrm{~mm}$-thickness $\& 0^{\circ}$ brace) and brace free cores were connected with $10 \mathrm{~mm}$-length columns. The value of $f_{\text {comp }}$ and $\varepsilon_{\text {comp }}$ were obtained from the corresponding one-core simulations as shown in Figs. 11(a) and 3(b), respectively. As shown in Fig. 13, the predicted curves (Prediction 1 \& 2) achieve good stress-strain shapes compared with corresponding experimental results. The predicted ultimate stresses and strains are also in close agreements with comparable experimental results as listed in Table 3, further validating their reliability for the composites with multiple cores. Moreover, the simulation with multiple brace-reinforced cores resulted in stiffer nonlinear responses, a lower ultimate stress and strain than that of the simulation without using braces as shown in Fig. 14. This trend 


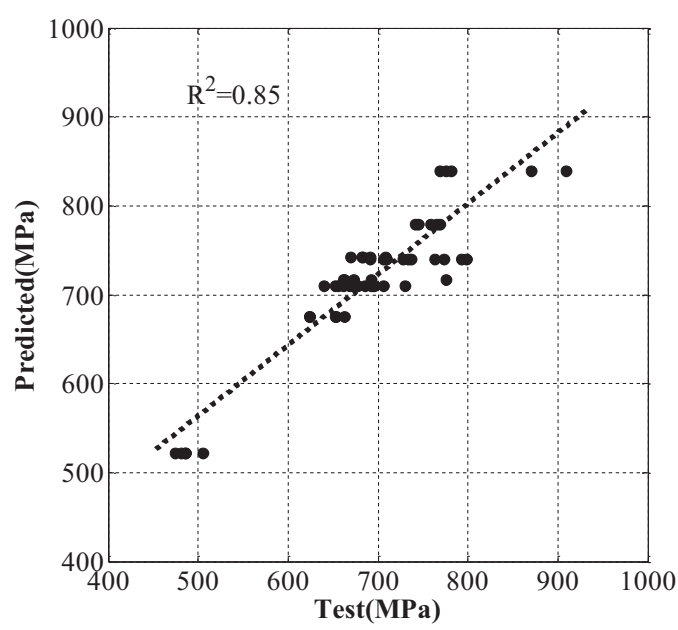

(a)

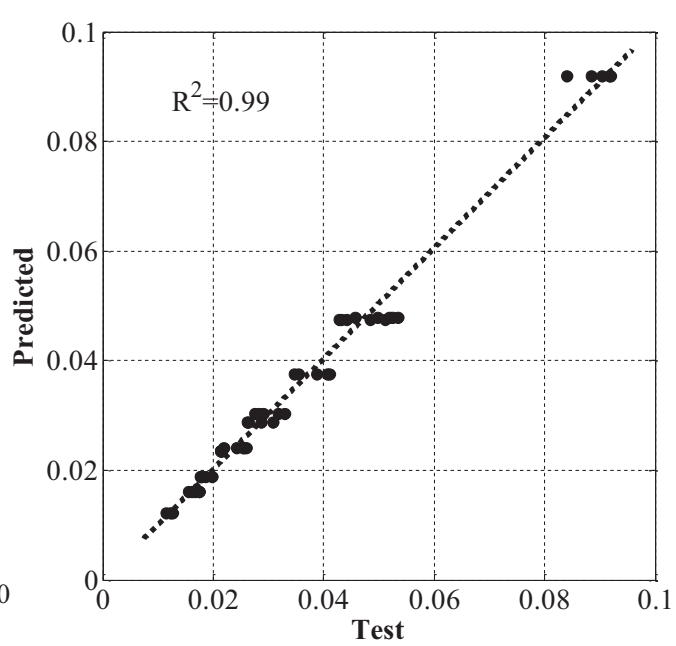

(b)

Fig. 15. Experimental results versus numerical predictions: (a) Ultimate stresses and (b) Ultimate strains.

is the same as that of the corresponding one-core simulations (see Fig. 12). Those suggests the proposed expressions are able to well predict the stress-strain relations for the composites with multiple cores.

\subsection{Ultimate stresses and strains}

In this study, simulations and expressions have been calibrated for the composite with various FRP amounts $(10 \sim 20$ mm-width strip used to make skins), $h_{c} / l_{c}(2 / 16 \sim 4 / 16)$, shell thicknesses $(1 \sim 2 \mathrm{~mm})$, core materials (ABS or PLA), brace arrangements (one $2 \mathrm{~mm}$-thickness \& $0^{\circ}$ brace or two $1 \mathrm{~mm}$-thickness \& $60^{\circ}$ braces) and core number $(1 \sim 3)$. As listed in Table 3 , the predictions in terms of ultimate stresses and strains are both within a good range from $92 \%$ to $110 \%$ of the corresponding experimental results, and a better range from $96 \%$ to $105 \%$ of at least one corresponding experimental results. Fabricating qualities, printing resolution and material variability allowed simulations to agree with certain experimental results better than others. Moreover, Fig. 15 shows that reasonably good coefficients of determination have been achieved by using the proposed computational tools to predict ultimate stresses $\left(R^{2}=0.85\right)$ and strains $\left(R^{2}=0.99\right)$, further validating the reliability. Therefore, the proposed FE model and expressions can be used to provide reliable ultimate stresses and strains for the proposed composites within the investigated range.

\section{Conclusions}

A 3D computational model has been developed for the highstrength, large-deformation and tensile-behavior designable FRP composite. Within the investigated range (strip width $=10 \sim$ $20 \mathrm{~mm}, h_{c} / l_{c}=2 / 16 \sim 4 / 16$, shell thickness $=1 \sim 2 \mathrm{~mm}$, core material $=\mathrm{ABS}$ or PLA, brace arrangement $=$ one $2 \mathrm{~mm}$-thickness $\& 0^{\circ}$ brace or two $1 \mathrm{~mm}$-thickness \& $60^{\circ}$ braces, and core number $=1 \sim 3$ ), numerical predictions agreed reasonably well with the corresponding experimental results in terms of entire stressstrain shapes, ultimate stresses and strains, validating the reliability of the proposed FE model. Based on the numerical predictions of one-core composites, expressions were proposed for quick determining the stress-strain responses for the corresponding composites with multiple cores. The predictions also showed good correlations with experimental results, indicating the reliability of the proposed expressions. Based on those predictions, the following conclusions may be drawn:

1. Increasing the amount of FRP material was expected to develop increasingly notable nonlinear responses, greater ultimate stresses and strains.

2. Similarly, a softer core in terms of a greater value of $h_{c} / l_{c}$, a thinner core shell, a core material with larger deformability, and brace free core also tended to result in increasingly notable nonlinear responses with increased ultimate strains.

3. Brace-reinforced composites were expected to achieve stiffer nonlinear responses but fracture skins at lower ultimate stresses and strains than that of brace free composites. Similarly, composites with a smaller brace angle tended to produce stiffer nonlinear curve with lower stresses and strains at skin fracture.

\section{Declaration of Competing Interest}

None.

\section{Acknowledgments}

The support of the National Natural Science Foundation of China [grant numbers 51608244], the Key Laboratory of Ministry of Education for Mechanics on Western Disaster and Environment, and the School of Civil Engineering and Mechanics at Lanzhou University, the Engineering and the Environment at University of Southampton are gratefully acknowledged. The authors express their thanks to Dr. Wang, Xingzhe for his kind willingness to share the laboratory with us.

\section{References}

[1] W. Sun, X. Peng, Y. Yu, Development of a simplified bond model used for simulating FRP strips bonded to concrete, Compos. Struct. 171 (2017) 462472, https://doi.org/10.1016/j.compstruct.2017.03.066.

[2] W. Sun, X. Peng, H. Liu, H. Qi, Numerical studies on the entire debonding propagation process of FRP strips externally bonded to the concrete substrate, Constr. Build. Mater. 149 (2017) 218-235, https://doi.org/10.1016/ j.conbuildmat.2017.05.117.

[3] W. Sun, J.O. Jirsa, W.M. Ghannoum, Behavior of anchored carbon fiberreinforced polymer strips used for strengthening concrete structures, ACI Mater. J. 113 (2016) 163-172, https://doi.org/10.14359/51688637.

[4] W. Sun, Development of a testing methodology for the design and quality control of carbon fiber reinforced polymer (CFRP) anchors, Constr. Build 
Mater. 164 (2018) 150-163, https://doi.org/10.1016/j.conbuildmat. 2017.12.192.

[5] W. Sun, W.M. Ghannoum, Modeling of anchored CFRP strips bonded to concrete, Constr. Build. Mater. 85 (2015) 144-156, https://doi.org/10.1016/ j.conbuildmat.2015.03.096.

[6] W. Sun, H. Liu, Y. Wang, T. He, Impacts of configurations on the strength of FRP anchors, Compos. Struct. 194 (2018) 126-135, https://doi.org/10.1016/ j.compstruct.2018.04.020.

[7] T. Lou, S.M.R. Lopes, A.V. Lopes, Effect of linear transformation on nonlinear behavior of continuous prestressed beams with external FRP cables, Eng. Struct. 147 (2017) 410-424, https://doi.org/10.1016/j.engstruct.2017.06.029.

[8] T. Lou, T.L. Karavasilis, Time-dependent assessment and deflection prediction of prestressed concrete beams with unbonded CFRP tendons, Compos. Struct. 194 (2018) 365-376, https://doi.org/10.1016/j.compstruct.2018.04.013.

[9] T. Lou, M. Liu, S.M.R. Lopes, A.V. Lopes, Effect of bond on flexure of concrete beams prestressed with FRP tendons, Compos. Struct. 173 (2017) 168-176 https://doi.org/10.1016/j.compstruct.2017.04.021.

[10] US Federal Highway Administration. Long-term effectiveness of cathodic protection systems on highway structures. Publ No FHWA-RD-01-096, FHWA 2001.

[11] B. Behnam, C. Eamon, Reliability-based design optimization of concrete flexural members reinforced with ductile FRP bars, Constr. Build. Mater. 47 (2013) 942-950, https://doi.org/10.1016/j.conbuildmat.2013.05.101.

[12] W. Sun, H. Liu, M. Achintha, C. Pan, T. He, A novel strong and ductile FRP system: concepts and experiments, J. Compos. Constr. (2019), https://doi.org 10.1061/(ASCE)CC.1943-5614.0000957 (accepted).

[13] P. Mohan, A critical review: the modification, properties, and applications of epoxy resins, Polym. Plast. Technol. Eng. 52 (2013) 107-125, https://doi.org/ $10.1080 / 03602559.2012 .727057$.

[14] Z. Zhai, L. Feng, G. Li, Z. Liu, X. Chang, The anti-ultraviolet light (UV) aging property of aluminium particles/epoxy composite, Prog. Org. Coat. 101 (2016) 305-308.

[15] S. Pimenta, P. Robinson, Wavy-ply sandwich with composite skins and crushable core for ductility and energy absorption, Compos. Struct. 116 (2014) 364-376, https://doi.org/10.1016/j.compstruct.2014.05.020.

[16] M. Jalalvand, G. Czél, M.R. Wisnom, Damage analysis of pseudo-ductile thinply UD hybrid composites - a new analytical method, Compos. Part A Appl. Sci. Manuf. 69 (2015) 83-93, https://doi.org/10.1016/j.compositesa.2014.11.006.

[17] G. Czél, M.R. Wisnom, Demonstration of pseudo-ductility in high performance glass/epoxy composites by hybridisation with thin-ply carbon prepreg Compos. Part A Appl. Sci. Manuf. 52 (2013) 23-30, https://doi.org/10.1016/ j.compositesa.2013.04.006.

[18] G. Czél, M. Jalalvand, M.R. Wisnom, T. Czigány, Design and characterisation of high performance, pseudo-ductile all-carbon/epoxy unidirectional hybrid composites, Compos. Part B Eng. 111 (2017) 348-356, https://doi.org/ 10.1016/j.compositesb.2016.11.049.
[19] C. Winkelmann, S.S. Kim, V. La Saponara, Design and development of hybrid composite bistable structures for energy absorption under quasi-static tensile loading, Compos. Struct. 93 (2010) 171-178, https://doi.org/10.1016/ j.compstruct.2010.06.002.

[20] C. Quon, L. Cheng, Y. Li, W. Yu, Confinement of concrete with hybrid FRP bistable structures, Cem. Concr. Compos. 37 (2013) 222-231, https://doi.org/ 10.1016/j.cemconcomp.2012.09.002.

[21] J.G. Dai, W.Y. Gao, J.G. Teng, Finite element modeling of insulated FRPstrengthened RC beams exposed to fire, Civ. Eng. 2 (2010) 1-15, https://doi. org/10.1061/(ASCE)CC.1943-5614.0000509.

[22] H.B. Pham, R. Al-Mahaidi, V. Saouma, Modelling of CFRP-concrete bond using smeared and discrete cracks, Compos. Struct. 75 (2006) 145-150, https://doi. org/10.1016/j.compstruct.2006.04.039.

[23] H.-T. Hu, F.-M. Lin, Y.-Y. Jan, Nonlinear finite element analysis of reinforced concrete beams strengthened by fiber-reinforced plastics, Compos. Struct. 63 (2004) 271-281, https://doi.org/10.1016/S0263-8223(03)00174-0.

[24] Y.F. Wu, Z. Wang, K. Liu, W. He, Numerical analyses of hybrid-bonded FRP strengthened concrete beams, Comput. Civ. Infrastruct. Eng. 24 (2009) 371384, https://doi.org/10.1111/j.1467-8667.2009.00596.x.

[25] X.Z. Lu, L.P. Ye, J.G. Teng, J.J. Jiang, Meso-scale finite element model for FRP sheets/plates bonded to concrete, Eng. Struct. 27 (2005) 564-575, https://doi. org/10.1016/j.engstruct.2004.11.015.

[26] G. Dean, L. Wright, An evaluation of the use of finite element analysis for predicting the deformation of plastics under impact loading, Polym. Test. 22 (2003) 625-631, https://doi.org/10.1016/S0142-9418(02)00168-X.

[27] S. Guessasma, S. Belhabib, H. Nouri, O. Ben Hassana, Anisotropic damage inferred to 3D printed polymers using fused deposition modelling and subject to severe compression, Eur. Polym. J. 85 (2016) 324-340, https://doi.org/ 10.1016/j.eurpolymj.2016.10.030.

[28] A.A. Ahmed, L. Susmel, On the use of length scale parameters to assess the static strength of notched 3d-printed pla, Frat Ed Integrita Strutt. 11 (2017) 252-259, https://doi.org/10.3221/IGF-ESIS.41.34.

[29] D. Farbman, C. McCoy, Materials Testing of 3D Printed ABS and PLA Samples to Guide Mechanical Design. Vol. 2 Mater Biomanufacturing; Prop. Appl. Syst. Sustain Manuf. 2016:V002T01A015. doi:10.1115/MSEC2016-8668.

[30] SAS, ANSYS 12.1 Finite element analysis system. SAS IP, Inc 2009; 2009

[31] S.R. Ghoreishi, T. Messager, P. Cartraud, P. Davies, Validity and limitations of linear analytical models for steel wire strands under axial loading, using a 3D FE model, Int. J. Mech. Sci. 49 (2007) 1251-1261, https://doi.org/10.1016/j. ijmecsci.2007.03.014.

[32] C. Erdonmez, C.E. Imrak, A finite element model for independent wire rope core with double helical geometry subjected to axial loads, Sadhana 36 (2011) 995-1008. 